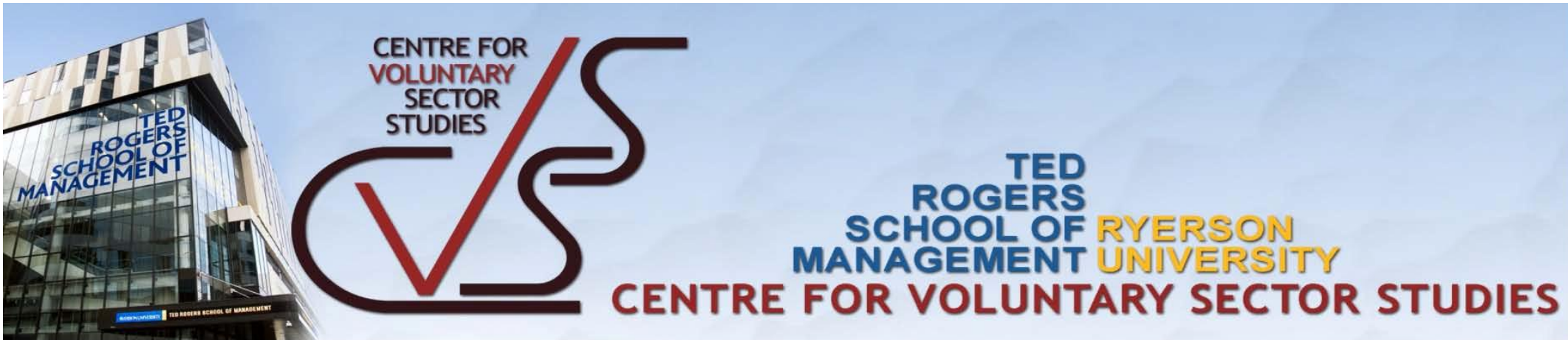

\title{
Competition or Collaboration? Preliminary Results of a Survey of Women's Voluntary Organizations ${ }^{1}$
}

\author{
Agnes Meinhard and Mary Foster \\ Centre for Voluntary Sector Studies, Ryerson University
}

Working Paper Series

Volume 1997 (3)

350 Victoria Street,

Toronto, Ontario, M5B 2K3

Tel: (416) 979-5000, x 6739 / Fax: (416) 979-5124

cvss@ryerson.ca

http://www.ryerson.ca/cvss/working_papers/

\footnotetext{
${ }^{1}$ This research was supported by a grant from the Social Sciences and Humanities Research Council.
} 


\title{
COMPETITION OR COLLABORATION? PRELIMINARY RESULTS OF A SURVEY OF WOMEN'S VOLUNTARY ORGANIZATIONS
}

\author{
Agnes Meinhard and Mary Foster \\ Centre for Voluntary Sector Studies, \\ Ryerson University
}

\begin{abstract}
This study examines the impact of current social, political and economic changes on women's voluntary organizations. Thirty eight leaders of women's voluntary organizations from across Canada were interviewed. Our findings show that although there is a sense of increased competition for scarce dollars, the favoured solutions do not focus on competitive strategies. Rather, collaboration is held up as the ideal.
\end{abstract}

\section{Introduction}

Women's organizations make up a considerable sub-sample of Canada's voluntary sector. Exact numbers are not available, but the National Action Committee on the Status of Women lists more than 600 member organizations under its umbrella, a number which, according to NAC, represents a mere fraction of women's organizations in Canada (NAC, 1996). This paper presents the concerns that leaders of women's voluntary organizations have in this climate of government cutbacks and neo-conservative political philosophy.

While all organizations exist in the same political and economic environment, and questions about the impact of the new social and fiscal reality are pertinent to all organizations, there are several reasons why women's organizations warrant separate attention. a) Women have special needs which often rank low in society's evaluation of what is important; b)Women place higher priority on social issues (Maclean's, September 30, 1996); c) Women's organizations are more dependent on government funding (Bradshaw et.al., 1996), making them more vulnerable in times of governmental cutbacks; d) Women's voluntary organizations have fewer alternative funding sources available to them because they are perceived to have less prestige (Bradshaw et.al., 1996) and because corporations are not generous in funding women's causes (Useem, 1987); e) There is increasing evidence to suggest that women organize differently with different board structures and different modi operandi, (Bradshaw et.al., 1996; Foster and Orser, 1994;

Odendahl, 1994; Perlmutter, 1994; Schein, 1975). All these factors can influence the way women's organizations respond to environmental pressures, placing doubt on the validity of generalizations from cross sectional studies.

\section{Review of Literature}

\section{Contextual Background of Canada's Voluntary Sector}

Voluntary and nonprofit organizations are playing an increasingly significant role in Canada's social, cultural and economic life. During the halcyon postwar years governments encouraged the formation of voluntary organizations. They were to be part of an elaborate social welfare system, allies of the state, extending specialized services that the government was uninterested in or unable to provide (Salamon, 1995). A large variety of voluntary organizations were created, representing a myriad of special interest groups. Not only did voluntary organizations receive generous funding from government sources, but more importantly they gained legitimacy to represent and serve their various constituencies (Tucker, Singh and Meinhard, 1990). It was during this period that government gave formal recognition to women's issues by creating the National Advisory Council for the Status of Women. This encouraged women to from 
organizations that addressed their needs and to seek governmental funding for them.

Since the mid-1980s, however, there has been a creeping erosion of the welfare state in Canada, as neo-conservative political philosophy has come to replace the social democratic liberalism of the postwar era (see McBride and Shields, 1997). Both the federal and provincial governments have been withdrawing from direct service provision in several areas of social welfare. With deficits out of control, they slashed their health, education and welfare budgets, including grants to the voluntary sector, by billions of dollars (Baker, 1996). This happening at a time when the country was undergoing a sustained period of recession. Expected to pick up the slack even as their budgets were being cut, voluntary organizations in Canada were in turmoil (Profile of a Changing World,1996).

\section{A Brief History of Women's Voluntary Organizations}

Women's voluntary organizations have long played an important role in women's lives as a window on broader public issues, as a source of skills development and as a vehicle for contributing to society. Trying to understand how women are affected by and are dealing with the current societal changes can best be done by investigating their organizational responses. Throughout history, women's organizations have been the venues through which women have agitated for changes affecting their lives and for the improvement of society as a whole. Until the influx of women into the work force in the latter half of the twentieth century, a woman's domain was almost exclusively in the domestic realm. Voluntary association was one of the few socially sanctioned extra-domestic activities available to women. Thus for many, volunteerism played a liberating role in their lives, giving them their only experience in the public realm (McCarthy,

1990). However, as long as decision making and funding remained in the hands of men, these voluntary activities continued to keep "women in their place." Participation was encouraged, but control was withheld (Kaminer, 1984:11). Frustrated, women began forming their own associations and by the mid-1800s, they were administering organizations in the fields of philanthropy, the arts and sciences, and social reform. This trend has continued into the present century. Despite the growing participation of women in the decision making bodies of large national voluntary organizations, $16 \%$ of which have women executive directors (O'Neill, 1994), women still favour joining women's organizations. McPherson and Smith-Lovin (1982) found that fully half the organizations they studied were exclusively female as opposed to only $20 \%$ that were exclusively male.

Recent historical studies point to the importance of women's voluntary organizations not only for women, but also for society as a whole. Whatever societal power women had in the last century, they achieved through participation in these organizations. Women's voluntary organizations gave voice to women's concerns and needs at a time when they were still disenfranchised (O'Neill, 1994). Even after they gained the vote, these groups continued to agitate for societal and legislative changes in women's status. Their impact was not only on the status of women. Women's benevolent societies formed a powerful lobby for social welfare legislation and strongly influenced the creation of the social welfare state (O'Neill, 1994). Women's organizations were both efficient and effective in carrying out their mission (A. Scott, 1990). They laid the foundations of the modern voluntary sector (Lewis, 1994; Odendahl, 1994). Women's organizations continue to give voice and aid to the marginalized and excluded of our society: Aboriginal women, women of colour, immigrants and refugees, single mothers and in general, the poor (NAC, 1996).

This history suggests that women were motivated to join voluntary organizations not simply to function as a marginal force in society desirous of advancing their cause and that of their constituents, but also to be an integral contributor to community values and the common good. Women's voluntary organizations have a rich history of contributions not only to the lives of women, but also to the voluntary sector and society as a whole (Perlmutter, 1994). Their activities 
have helped shape the character and nature of the voluntary sector as we know it today (Odendhal, 1994).

\section{Method}

In hour-long, in-depth, taped telephone interviews, 38 Executive Directors or Presidents of women's voluntary organizations from across Canada were asked:

1. How they perceive and interpret the sociopolitical changes that are occurring in Canadian society?

2. How their organizations responding to these changes? Specifically:

a) What role do they see for voluntary organizations in this new sociopolitical configuration?

b) What role do they see for their own organization?

c) What strategies have they implemented, or are they thinking of implementing, both within their organizations and in relation to other organizations?

The interviews were transcribed and content analysed.

The sample was derived from National Action Committee on the Status of Women's list of member organizations. In order to include a variety of organizations differentiated by size and primary mandate, we had to contact approximately 120 organizations. Although the resulting sample of 35 organizations is not fully representative, we did succeed in ensuring a broad representation of organizations according to size, mandate and geographic region.

Size: Kimberly (1976) identified four conceptually independent aspects of organizational size: a) physical capacity, b) personnel available, c) inputs / outputs and d) discretional resources available. The choice of measurement depends on the objectives of the research. Since this study focuses on organization-environment transactions, resource availability, as measured by annual revenue, was the criterion for size. Our sample contained 20\% small (less than \$100,000) 60\% medium $(\$ 100,000-\$ 600,000)$ and $20 \%$ large (more than $\$ 600,000)$ organizations.

Mandate: Most women's voluntary organizations fall into one of three basic categories: social services (e.g. Elizabeth Fry Society), health services (e.g. Women's Health Clinic), and a cluster that we label education/advocacy/lobbying (e.g. National Action Committee on the Status of Women). Although these often overlap, each organization has a primary mandate in one of these areas. These include promoting reproductive choice, pre-employment counselling, crisis services such as women's shelters and rape crisis centres, information sharing in women's centres, obtaining recognition for working women and providing legal support.

Geography: At least two organizations from each province were inclu ded in the sample, with the three largest provinces, British Columbia, Ontario and Quebec having greater representation.

Definitional requirements: To qualify for inclusion in the sample the organizations had to fulfil the definitional requirements of a voluntary organization (Johnson 1981:14): a) that the organization does not owe its existence to statutory authority, but consists of a group of people who have come together voluntarily; b) the organization is self governing and decides its own constitution and policy; and c) the organization is non-profit making. To be classified as a women's voluntary organization, $80 \%$ of board members and the Executive Director had to be women. 


\section{Results}

The in-depth interviews focused on a) identifying the central trends and events in the external environment that were having an impact on the voluntary sector, and specifically the respondent's organization, and b) investigating the behavioural and attitudinal responses associated with these trends. Despite the differences in organizations' location, size, tenure and main mandate, there were three key findings related to the objectives of the interviews that apply to all respondents. First, all organizations feel there has been a dramatic shift in the economic priorities of governments at both the provincial and federal levels. Second, there has been a range of behavioural and attitudinal responses to this environmental change ranging from proactive to reactive. Finally, despite the range of responses and individual differences among organizations, all anticipate that some form of collaboration is in their future.

\section{Economic Changes}

Changes in the economic priorities of governments have had a significant impact on organizations both directly and indirectly. First the "cutback kind of agenda" of the government has reduced direct funding to organizations at the same time as the government is stepping out of its role as a service provider. The few organizations which have received increases in funding find that the extra dollars available are not sufficient to cover the services "downloaded" from government that they are supposed to cover. In general, all organizations across Canada feel they have to "do more with less".Funding cuts have reduced the ability of organizations to deliver programs and services. At the same time, the retrenchment within the economy as a whole has increased the number of potential social service users.

A few organizations see a conspiratorial edge to the policy initiatives of current governments. "I think there is a real right wing kind of agenda happening out there keeping people poor, keeping people out of the work force." Others feel that the government has not fully considered the consequences of its actions. "People are really clawing away, and as much as they want to stay in the work force, the child care isn't there for them, so they're better off staying home being on welfare and that's the reality that women face." By cutting the supports necessary to get into the work force, governments are acting as unwitting enablers for people to stay on welfare.

A few organizations are very pessimistic about the outcome of this type of economic climate. They fear that these policies may have a long-term effect on societal values. "There was a time when there just seemed to be lots of opportunity, as long as the pers on had the initiative and the drive to further their education, but...the brakes have been put on." The old strategies for getting ahead do not seem to be working, and some organizations are concerned about the limited discussion to date of viable alternatives.

\section{Responses to Changes in Economic Priorities}

The reaction to the changes in economic policies is both varied and complex. Some organizations demonstrate reactive attitudes and values, as they present themselves somewhat like victims who have no control over their destiny and are catapulted from one crisis to the next at the whim of the government. Others demonstrate proactive attitudes and behaviours, as they intend to use the imposed economic difficulties as a catalyst for self-reflection, refocusing and in some instance re-organization. Finally, there are organizations whose attitudes and behaviours are a combination of reactive and proactive.

The majority of organizations feel that the situation for the voluntary sector has worsened as a result of the current economic climate. Some express this as increased vulnerability. "We certainly feel that we are more vulnerable than we have ever felt before, and we don't trust that their (the government's) intentions, their directions, their signals are going to be good." As a consequence of these feelings, some organizations feel incapable of doing any future planning. 
"The cutbacks kick down so fast that you couldn't plan ahead. It was almost like you were thrown into crisis mode and you react accordingly."

A few organizations have adopted a definite "we-they" mentality as they describe their concerns about taking a public position on government policies. "We have always had a strong political voice, although this particular time feels like the most dangerous to have one." This fear of reprisals means that more organizations are collaborating around political issues. "If we don't, there is a great deal of risk that individual shelters would be singled out for negative kinds of treatment."

The increased feeling of vulnerability described by some organizations is not just for thems elves, but also for their constituents. "Our front-line workers report that it is clear to women that they're not valued, that the impact of these cuts is that their lives and situations are not valued, and that it's easier for them to see themselves as victims."

Consistent with the historical role of women's organizations as the voice for the disadvantaged, about one third of respondents raise concerns that the cutbacks have been made on the backs of "the most vulnerable in our society." To take this targeting one step further, a few feel that a "hardening of attitudes" has resulted, such that "the poor and the underprivileged and the marginalized are to blame for all the things that are happening."

Two-thirds of respondents mention political action as an important aspect of the current environment. Those with a more proactive mind set are using political action, lobbying and advocacy as a way of influencing and ultimately controlling the agenda for the voluntary sector. For some, this is a new focus. "For the first time in ten years, the board... actually agreed to have their banner at our anti-government march." "....A lot of people in our social justice committee took on a role to work with a political party...and most of us hadn't done that before."

For others, it is a continuation of activities that have always been a part of their organization. "We have done a lot of advocacy over the years...we've formed coalitions...but we also do a lot on our own." However, what has changed is that they are more persistent and aggressive in these activities. "We are out there; we're talking to the media (and) the press, letting them know that there is a problem, that it's not going away regardless of what Stats Canada wants you to believe...".

Advocacy continues to be a key defining characteristic of the voluntary sector because organizations believe that it works. "Most of the organizations that we belong to make representations to the federal and provincial governments of their respective groups; and it's kind of a matter of trying to organize the numbers. If we put pressure on any level of government, they will eventually start paying attention and do something about it."

About a third of the organizations have laid off or restructured their staff complement. For about one-quarter service offerings have also been reduced. However, this is often linked with refocusing or narrowing their mandate to their core services or reducing hours of operation or staffing during slack times to work within budget constraints. "We haven't laid anybody off, but what we did do instead was that we switched our scheduling around so now instead of having a double staff line, two staff lines are open on an overnight shift, we have one line open."

In order to increase their autonomy and reduce dependence on government funding, about a third of the organizations are increasing their marketing activities in order to secure other funding sources. "It's the first time that we're going to actually take some steps into the corporate sector and actually market our services." However, this adopting of a more entrepreneurial and marketing perspective is not without its costs. "You can't be inflexible in an economic climate like this, but at the same time you can't sacrifice your philosophy or your mandate to reach that goal. I 
think it has to be a marriage of the two. Definitely, for example, we'd take money now from people that we never have taken money before and we have no choice but to do that because the goal is always to improve your service, and if you have to do that in a way that maybe you're not too thrilled about, but you can live with...Again we felt that (if) the point (was) that more women would be serviced, then that should be the priority. But, there has to be some middle ground; something that we will not do."

About one-half of respondents indicate that their organizations are focusing more on strategic planning. However, some are using strategic planning in a reactive way; that is coping with cost cuts. "...one of the questions is how to solidify the funding base, so that we don't have to cut stuff that's important. So it's a matter of deciding what you can and can't do and what you will not give up."

Others view strategic planning proactively. "We also try to respond to emerging issues, so we are reactive to some extent, but there is a real thrust to do some forward thinking; and we do have strategic goals as to how we want the organization to develop in the future."

\section{Competition}

Two-thirds of respondents mention the introduction of a competitive atmosphere into the voluntary sector. "Socially, for women's organizations, it's very difficult because now we're basically fighting for the same dollars. The dollars are shrinking and shrinking, so in terms of cohesiveness within the women's movement...it's becoming more difficult; (it's) divide and conquer." For some, this competitive culture is under the guise of efficiency. "I hear myself saying: let's get focused; let's get tight; let's get efficient. It almost feels a bit competitive."

There are positive elements to embracing a more competitive view of operations. "Competition is healthy. It's not bad. It makes sure that nobody gets to sit on their ass and just get a free ride anymore. It makes it so you work harder on your services. You always have to be keeping up-to-date with things, and that's good." On the other hand, several organizations predict the possibility for very negative consequences for clients from such a shift in culture. "One would wonder whether it (being competitive) would be that you do your services for the lowest dollar and so being competitive in that way doesn't necessarily translate into good service. It's translated into bad service."

Relations among organizations can also be affected by competition. "This social and economic climate has put a strain on the organizations and there are some hurt feelings between individuals and agencies because of the stress and the competitiveness; some walls have been put up." However, others are clearly alerted to the danger that exists in adopting a competitive mind set and are taking steps to ensure that the sector as a whole does not suffer. "I think we have to be very, very careful that we don't start applying for each other's money and coming out with projects to get money to keep doors open that other people would normally be working on those projects. We have to be very careful that we don't do that to each other." "What I don't like is that I really do feel that the government is trying to turn us one against the other."

\section{Collaboration}

Despite the recognition of both the positive and negative aspects of competition, organizations in this study are much more likely to embrace a collaborative way of operating. "Sure there's an awareness that we can't all be doing the same thing and I think we're alert to the fact that we want to protect what we see as our turf, but to our credit, there has been put in place a community organization where managers of volunteers or office managers and volunteer agencies are coming together to make sure that there isn't that duplication."

More than $80 \%$ of respondents mention participating in collaboration in its many forms 
ranging from sharing information to sharing resources to working collectively on projects or programs. The voluntary sector is clear that it has a very broad definition of what is included in collaboration. "I think the government's idea of collaboration and our idea of collaboration are different. We've always collaborated. We have always been intimately connected and working together in this community. The government's idea of collaboration is that...you all get together so you absorb the cuts."

The most basic level of collaboration is sharing information. Some do it on an informal basis. "Locally...the other Executive Directors...get together and that is for all of us a very key meeting... because we share information. It helps us survive...It gives us information as to how we can do better for our clients...and for our agencies." The theme of mutual support is also illustrated in more formalized structures. "In our community, we have a group called the Interagency Council and its members are each of the social services. It's typical of communities. I guess we get together and we try to come up with filling the gaps in services and just kind of working together, sharing the struggle."

For some organizations, the collaboration has to do with ensuring that resources are used appropriately and there is no duplication of efforts. "Actually, over the past few months we've met with a number of other associations, unions and guilds that work within the industry and (with) some that are professionally related, like colleges and universities to find out what they do so we don't duplicate the services that we offer." Other organizations search for partners that have skills which they don't have. "We've entered into a partnership with AT\&T Canada where we use their language line service so now we can service women in 140 different languages."

Other partnerships are based more on the desire to survive the cutbacks and continue to exist. "We are sharing office space with another organization, both here and in Medicine Hat...We share expenses like fax and photocopy." Some of the collaborations are non-specific. "...we pay attention to what other women's organizations are doing and try to help in any way we can."

Many see the value of collaboration as increasing the voice of the cluster of organizations with whom they relate. "I think that kind of solidarity could really strengthen the whole shelter network." But several, see it as an opportunity to increase the clout of the whole sector. "So instead of us initiating our own little stuff on our own, we're trying to work with broader based coalitions that are commenting, for example, on workfare or the megacity." Much of this type of collaboration revolves around political action which was mentioned as a theme by two-thirds of the organizations in the study.

Collaborating as a strategy forces organizations to do some self-reflection and look into the future. It is not an easy route to solving all the problems of the voluntary sector. Working with others requires time, effort and commitment because "it's really hard to look at the big picture when you're just trying to keep your doors open.”.

\section{Discussion}

Jacquelyn Thayer Scott (1992) outlined the history of Canada's voluntary sector from 1685 to the present and concluded that voluntary organizations reflect their environment and the prevailing philosophies of state. Based on Van Til's (1988) classification of different models of volunteering, Scott identified the two predominant models that have characterized the Canadian voluntary sector in the latter half of the twentieth century: The pluralistic social welfare model which informed the voluntary sector during the three postwar decades, and the neo-conservative model, which is replacing it. Both these models reflect an individualistic, competitive society, one in which both people and organizations compete to attain their needs (Neal and Paris, 1990). 
The pluralist model sees the voluntary sector playing a distinctive role in society, one that involves interaction with the state. Voluntary organizations represent special interest groups that are not part of the establishment. Their function is not only to provide direct service to their constituents, but also to engage in advocacy and social change. This may place them in conflict with the state and/or the for-profit sector. Their focus is more on serving their members and constituents than on advancing the common good, although the two often go hand-in-hand. Because they see themselves in competition with other organizations, they concentrate on organizational strategies and programs that will assure them a sociopolitical niche. The board's primary concern is advocating public policy favourable to the organization (Gidron et. al., 1992; Scott, 1992, 1995; Van Til, 1988).

In the neo-conservative model, the voluntary sector has no special role and is marginal to the main economic and political forces in society. Market forces should dictate the formation and survival of all organizations, including nonprofit organizations. Funding for nonprofit organizations must come from private charitable support and user fees, not from government. Thus, governments espousing neo-conservative philosophy have not only withdrawn from providing direct services, but they have also decreased funding to the voluntary sector. Voluntary agencies, therefore, find themselves competing with other organizations for essential financing, so their focus is on management control, marketing and entrepreneurship. The principal role of the board is fundraising (Scott, 1992; Van Til, 1988).

All organizational leaders in this study attested to a movement away from bountiful government funding to a neo-conservative attitude of government devolution. From the interviews, it is clear that many of the organizational leaders, whose organizations were founded during the pluralistic era, still see advocacy and lobbying as an important aspect of their mandate. Whereas in the past organizations operated in a climate in which governments encouraged and supported voluntary sector activity, and recognized this role as legitimate, now they are more fearful of repercussions, given the adoption of a more conservative political outlook by all federal and provincial governments, regardless of political party. Many no longer see government as a partner as much as an adversary who is dictating new terms that will affect the survival of the organization. This having been said, our evidence indicates that many organizations are taking heed of the new atmosphere and are adopting more entrepreneurial and businesslike attitudes in their day to day management. These findings support, in part, results from a recent survey of 85 voluntary social service organizations in Metro-Toronto, which indicate that voluntary organizations have started to embrace activities with a business focus in order to gain competitive advantage with both private and corporate donors (Foster and Meinhard, 1996).

Such competition would be endorsed by neo-conservative philosophy important in weeding out the poor performers. However, in the voluntary sector, the correlation between performance in terms of providing a good service, and ability to survive is not straightforward. The danger is that those organizations serving the neediest sectors of society are probably the very ones that would find it most difficult to compete for funds. This is true for many women's organizations. Women's causes rank low in society's evaluation of what is important. Thus, women's voluntary organizations are perceived to be less prestigious; and consequently, would be at a disadvantage competing for corporate dollars to make up for the decrease in government funding. Another possible negative consequence of neo-conservative strategies in voluntary organizations is that excessive concentration on fundraising and economic management in response to competitive pressures may lead the voluntary organization away from its charitable mandate and diminish its ability to respond to the needs of the disadvantaged (Salamon and Anheier, 1996).

Indeed, these fears were expressed in several ways during the course of the interviews. Although they were concerned with the implications of increased competition, the majority of women's voluntary organizations in this study were engaged in a wide range of cooperative beha viours with other organizations. In fact, several clearly expressed the conviction that 
cooperation through community participation, expansion of services across several community actors, creation of partnerships across sectors, and empowering their members and clients in the decision making processes, was the key to organizational survival.

Thus, women's organizations are rejecting the competitive, neo-conservative model of the voluntary sector, which maintains that market forces should dictate the formation and survival of all organizations, including nonprofit organizations, and endorses competition as healthy, in that it would weed out the poor performers. They are instead showing evidence of moving toward a communitarian model. This philosophy holds community values and the common good paramount. Voluntary organizations "are not mediating structures, but actualizing instruments of the commonweal" (Scott, 1992:384, original italics). As such they focus on community building, through interaction with other service givers, through partnerships with organizations in other sectors and through co-production with clients. The board's principal role is governance and adherence to values of its mission. "Board members occupy their positions on behalf of the community" (Scott, 1995:36). There are examples of this in the private corporate sector as well. Lodge (1991) was the first to distinguish between individualistic British-American capitalism, and communitarian Japanese-German capitalism. In the latter model, companies believe they should be financially interlocked and work together to strengthen each others' activities (Thurow, 1992.)

There is evidence in the literature to suggest that cooperation, inclusion and empowerment would be a preferred mode of behaviour for women. Females are socialized to be nurturing and relationship oriented (Cooper, 1992; Grant, 1988; Rosener, 1990), as opposed to males, who are taught to be competitive, hierarchical and independent (Harragan, 1977; Henning and Jardim, 1976; Gilligan, 1982). Of course, individuals may experience different socialization patterns, but in aggregate, the patterns for males and females hold true (Eagly, 1987; Gilligan, 1982). Gilligan's (1982) groundbreaking study, In a Different Voice, documents in case after case, the importance of inclusiveness and relationships in women's lives. They view morality through the spectrum of the common good, and judge actions in terms of how they will affect relationships. Men, on the other hand, have a more abstract concept of justice, one concerned more with the protection of individual rights than with an appreciation of the common good. Where women seek relatedness, men strive towards independence. Thus, women and men approach the world and organize their activities in different ways. Lever's (1976, 1978) classic study of boys and girls at play points to early differences in interaction models. Boys are task-oriented, creating complex rules within a context of distinctly defined hierarchical roles, whereas girls develop complex networks of relationships with shifting roles. Both achieve their goals, but in different ways.

Currently, the structure of most corporate and voluntary sector organizations mirrors the male emphasis on competition, hierarchy and task orientation, which Harragan (1977) and others (Henning and Jardim, 1976) describe as an "alien culture" to women. Conversely, women's interaction patterns reflect an atmosphere of community rather than hierarchy (Tannen, 1990). This is evident in the voluntary sector where many women's organizations, despite the strong forces of institutionalization to create traditional structures, (Odendahl and Youmens, 1994) are eschewing the hierarchical model for ones that are more inclusive, consensual and empowering (Lot, 1994).

Not only is the spirit of inclusiveness evident within women's organizations through their leadership patterns and organizational preferences, but it is also evident in their interorganizational patterns. The National Action Committee on the Status of Women forms by far, the largest umbrella organization in the Canadian voluntary sector. Under the leadership of NAC's executive, which is made up of representatives from member groups from across the country, these women's organizations share resources and form a powerful lobby to effect changes that will benefit not only their constituents, but also society as a whole. Despite attempts in recent years, the general voluntary sector has failed to form a powerful umbrella group such as NAC. Interorganizational cooperation in pursuit of the common good forms the basis of the communitarian 
model.

\section{Conclusion}

The findings indicate that organizations are making changes as a result of the shift in the division of responsibility between the government and the third sector. Many fear for their future. Some are in reactive crisis mode, and focus on survival by adopting cost-cutting measures, including reductions in services, activities and/or staff. Other organizations are using the funding crisis as a catalyst for long-term strategic planning. Most admit that the funding cuts are forcing them to become more efficient and accountable. Regardless of the immediate response to the external situation, all organizations see collaboration and partnership as a key operational strategy in the future. All have formal or informal links with other organizations through which they share information, and often resources as well. Although there is a sense of increased competition for scarce dollars, the favoured solutions do not focus on competitive strategies. Rather, collaboration is held up as the ideal. Women's organizations' choice of inclusive, cooperative, communitarian strategies may be the archetype of the voluntary sector of the future.

\section{References}

Baker, J. 1996. Metro Toronto Social Planning Council. Personal Communication.

Bradshaw, Pat, Murray, Vic and Wolpin, Jacob. 1996. "Women On Boards Of Nonprofits: What Difference Do They Make?" Nonprofit Management and Leadership, 6:241-254

Cooper, C. 1992. Quoted from page 309 in Syrett, M. and Hogg, C. (Eds.). Frontiers of

Leadership: $\quad$ An Essential Reader. Oxford: Basil Blackwell.

Foster M.K. and Orser, B.J. 1994. "A Marketing Perspective On Women In Management: An Exploratory Study," Canadian Journal of Administrative Sciences, 11:339-345.

Foster, M.K. and Meinhard, A.G. 1996. "Toward Transforming Social Service Organizations In Ontario." Presented at Babson Conference on Entrepreneurship, Seattle, WA

Gidron, Benjamin, Kramer, Ralph M. and Salamon, Lester M. 1992 Government and the Third

Sector: $\quad$ Emerging Relationships in Welfare States. San Francisco: Jossey-Bass.

Gilligan, C. 1982. In a Different Voice. Cambridge: Harvard University Press.

Grant, J. 1988 . "Women as managers: what they can offer organizations." Organizational Dynamics, 16.

Harr agan, B. L. 1977. Games Mother Never Taught You. New York: Warner Books. Henning, M. and Jardim, A. 1976. The Managerial Woman. New York: Pocket Books. Kaminer, W. 1984. Women Volunteering. Garden City: Anchor Press.

Lever, Janet. 1976. "Sex Differences in the Games Children Play." Social Problems, 23:478483.

Lever, Janet. 1978. "Sex Differences in the Complexity of Children's Play and Games."

American Sociological Review, 43:471-483.

Lodge, George C. 1991. Perestroika for America. Boston: Harvard University Press. Pp. 1516.

Lott, J.T. 1994. "Women, Changing Demographics And The Redefinition Of Power." In Odendahl, T. and O’Neill, M. (Eds.) Women and Power in the Nonprofit Sector. San Francisco: Jossey- Bass.

McBride, S. and Shields, J. 1997. Dismantling a Nation: The Transition to Corporate Rule in Canada. Halifax: Fernwood Publishing.

McCarthy, Kathleen, D. 1990. Lady Bountiful Revisited: Women, Philanthropy, and Power.

New Brunswick: Rutgers University Press.

McPherson, J.M. and Smith-Lovin, D.L. 1982. "Women And Weak Ties: Differences By Sex In

The Size Of Voluntary Organizations." American Journal of Sociology, 87:883-904.

NAC (National Action Committee on the Status of Women), 1996. Personal communication. 
Neal, P., and Paris D. 1990. "Liberalism And The Communitarian Critique: A Guide For The Perplexed." Canadian Journal of Political Science/Revue canadienne de science politique, 23:419-439.

Odendahl, T. and Youmans, S. 1994. "Women On Nonprofit Boards." In Odendahl, T. and O'Neill, M. (Eds.) Women and Power in the Nonprofit Sector. San Francisco: Jossey-Bass. O’Neill, M. 1994. "The Paradox Of Women And Power In The Nonprofit Sector." In Odendahl, T. and O'Neill, M. (Eds.) Women and Power in the Nonprofit Sector. San Francisco: Jossey- Bass.

Perlmutter, F.D. 1994. Women \& Social Change: Nonprofits and Social Policy. Washington: National Association of Social Workers.

Profile of a Changing World: 1996 Community Agency Survey. 1997. Toronto: Metro Toronto, City of Toronto and SPC.

Rosener, J. B. 1990. "Ways Women Lead.” Harvard Business Review, 68: 109-125.

Salamon, L.M. 1995. Partners in Public Service: Government-Nonprofit Relations in the Modern Welfare State. Baltimore: The Johns Hopkins University Press.

Salamon, Lester M. and Anheier, Helmut K. 1996. The Emerging Nonprofit Sector: An

Overview. Manchester: Manchester University Press.

Schein, V.E. 1975. "Relationship Between Sex Role Characteristics And Requisite Management Characteristics Among Female Managers.” Journal of Applied Psychology, 57: 95-100

Scott, Jacquelyn T. 1992. "Voluntary Sector In Crisis: Canada's Changing Public Philosophy Of

The State And Its Impact On Voluntary Charitable Organizations." Ann Arbor: University Microfilms.

Scott, Jacquelyn T. 1995. "Some Thoughts on Theory Development in the Voluntary and

Nonprofit Sector." Nonprofit and Voluntary Sector Quarterly, 24:31-40.

Tannen, Deborah, 1990. You Just Don't Understand. New York: Ballantine Books.

Thurow, Lester. 1992. Head to Head. New York: William Morrow \& Company Inc. Pp. 32-

34.

Tucker, D.J., Singh, J.V. and Meinhard, A.G. 1990. "Organizational Form, Population Dynamics

And Institutional Change: A Study Of Birth Patterns Of Voluntary Organizations." Academy of Management Journal, 33:151-178.

Useem, M. 1987. "Corporate Philanthropy." In Powell, W.W., (Ed.). The Nonprofit Sector: A Research Handbook. New Haven: Yale University Press.

Van Til, John. 1988. Mapping the third sector: Voluntarism in a changing social economy.

New York: Foundation Center. 